\title{
Performer Postal Address
}

National Cancer Institute

\section{Source}

National Cancer Institute. Performer Postal Address. NCI Thesaurus. Code C93983.

A contact point used to send physical forms of communication to the performer. 